\title{
Estado Democrático de Direito e a Participação Popular no Brasil: Uma Análise a Partir do Conceito de Luigi Ferrajoli
}

\author{
Luciana Oliveira de Campos \\ Advogada pública. Mestrado em Direito pela Universidade La Salle - Canoas/RS. Especialização \\ em Direito Público pela Faculdade IDC. http://lattes.cnpq.br/3807057574671613. https://orcid.org/0000-0002-2432-0012. \\ luciana47853@gmail.com \\ Leonel Pires Ohlweiler \\ Mestrado e Doutorado em Direito pela Unisinos. Desembargador do Tribunal de Justiça do Estado do Rio Grande do Sul. \\ Professor da Universidade La Salle - Canoas/RS. http://lattes.cnpq.br/7121357651277765. https://orcid.org/0000-0002-2296-675X. \\ leonelpires@terra.com.br
}

O presente estudo tem como objetivo propor uma reflexão sobre o Estado Democrático de Direito e o exercício da democracia direta no Brasil à luz do garantismo como paradigma teórico. A análise dar-se-á com base nos aportes de Luigi Ferrajoli, segundo o qual as garantias constitucionais limitam e vinculam os poderes, com implicações de ordem jurídica e democrática, compreendendo desde a separação entre existência e validade nos aspectos formal e substancial, até uma teoria quadridimensional da democracia fundada nos direitos políticos, civis, de liberdade e sociais. Sob esse olhar garantista, a participação popular, realizada mediante a aproximação dos cidadãos dos centros de decisão, que está para além do exercício da democracia de forma direta assegurada no texto constitucional, deve ser considerada importante instrumento nos processos de efetivação dos direitos fundamentais, especialmente dos direitos sociais constitucionalmente assegurados. Adota-se a metodologia qualitativa e a coleta dos dados por meio de pesquisa bibliográfica.

Palavras-chave: Estado Democrático de Direito. Constitucionalismo. Garantismo.

\section{RIGHT OF DEMOCRATIC STATE AND POPULAR PARTICIPATION IN BRAZIL: AN ANALYSIS FROM THE LUIGI FERRAJOLI CONCEPT}

\section{ABSTRACT}

This study aims to propose a reflection on the Democratic State of Law and the exercise of direct democracy in Brazil in the light of the guaranteeism as a theoretical paradigm. The analysis will be based on the contributions of Luigi Ferrajoli, according to which constitutional guarantees limit and bind powers, with juridical and democratic implications, ranging from the separation between existence and validity in the formal and substantial aspects until a four-dimensional theory of democracy founded on political, civil, freedom and social rights. Under this garantism view, the popular participation achieved by bringing citizens closer to decision centers is beyond the exercise of democracy directly guaranteed in the constitutional text, must be considered as an important instrument in the processes of realization of fundamental rights, especially of social rights constitutionally ensured. The qualitative methodology and the data collection are adopted through bibliographic research.

Keywords: Democratic State of Law. Constitutionalism. Guaranteeism.

\section{SUMÁRIO}

1 Introdução. 2 Estado Democrático de Direito e o novo paradigma constitucional. 3 Os direitos fundamentais e o modelo de democracia quadridimensional. 4 Participação popular no Brasil sob a ótica do novo paradigma constitucional. 5 Considerações finais. 6 Referências. 


\section{INTRODUÇÃO}

Após a Segunda Guerra Mundial, mudanças voltadas especialmente a assegurar direitos fundamentais restaram instituídas nas constituições de um grande número de países, as quais foram transformadas em constituições rígidas com força normativa, tutelares de princípios e direitos fundamentais positivados. Essas mudanças provocaram inúmeros reflexos sobre o Estado de Direito e sobre a concepção de democracia. Desde então, tais alterações são objeto de estudo, sobre o qual se debruçam inúmeros e renomados juristas.

$\mathrm{Na}$ condição de norma suprema, essas constituições trazem, em seus textos positivados, além de direitos de liberdade, os direitos sociais com carga obrigacional imposta a todos os poderes. Os princípios e direitos fundamentais, reconhecidos nessa nova concepção de constituição, estão envolvidos por um manto de proteção de tal forma que não podem ser alterados ou excluídos dos textos constitucionais, nem mesmo por decisão de maioria.

Ante essa nova realidade, Luigi Ferrajoli aborda o constitucionalismo como um novo paradigma. $\mathrm{O}$ autor sustenta que o garantismo, o qual surgiu na Itália, no campo do direito penal e processo penal, como teoria de oposição à redução de garantias de direitos de liberdade, "deve ser ampliado em sede de teoria geral do direito para todo o campo dos direitos da pessoa" (2015, p. 30).

O garantismo, como teoria geral do direito, tem como base as garantias constitucionais, as quais impõem uma série de limites e vinculações a todos os poderes - Executivo, Legislativo e Judiciário - voltados a assegurar a efetividade dos direitos e princípios constitucionais, avançando para além dos direitos de liberdade, no sentido de impor um dever prestacional de efetivação de direitos sociais.

A subordinação da atividade legislativa à constituição dá nova dimensão à democracia. Sob o manto das garantias, os direitos assegurados são protegidos até mesmo de uma decisão majoritária, infligindo, assim, relevantes mudanças sobre a concepção de democracia, a qual deixa de ser apenas formal (representativa), devendo ser também substancial.

Este estudo, que adota a metodologia de pesquisa bibliográfica, tem como objetivo propor uma reflexão sobre o Estado Democrático de Direito e o exercício da democracia direta no Brasil por meio de mecanismo de participação popular à luz do conceito de Luigi Ferrajoli. Com tal intuito, pretende-se desenvolver o presente trabalho em três tópicos. No primeiro, far-se-á uma breve síntese acerca do Estado Democrático de Direito e do novo paradigma constitucional. Na sequência, procurar-se-á discorrer sobre a inclusão de direitos fundamentais no texto constitucional e o modelo de democracia quadridimensional. Por fim, pretende-se abordar a participação popular no Brasil, entendida como o exercício da democracia direta sob a ótica do novo paradigma constitucional, notadamente da democracia substancial.

\section{ESTADO DEMOCRÁTICO DE DIREITO E O NOVO PARADIGMA CONSTITUCIONAL}

No Estado Democrático de Direito estão contidos os elementos formadores do Estado de Direito, o qual nasceu a partir do desejo da burguesia de impor limites ao absolutismo da monarquia, tendo como principais características o império da lei, a divisão dos poderes e as garantias de liberdade. Há, contudo, um avanço importante relacionado à inclusão de garan- 


\section{Humanos e \\ Democracia}

tias de direitos fundamentais dos indivíduos, típicas do Estado Social, no sentido de assegurar além dos direitos de liberdade e de um regime político em que o poder provenha da vontade geral do povo para incluir direitos prestacionais.

A democracia, centrada na soberania popular, em que o "poder político é exercido pelo povo" (BOBBIO, 1987, p. 135), é, na verdade, um conceito que sofre alterações ao longo da história, guardando relação direta com os direitos políticos, com a participação na vida política e com a limitação do poder.

Norberto Bobbio (1987, p. 140), com base no conceito axiológico de "democracia dos antigos", discorre acerca de diferentes posições registradas no que se refere à democracia, como a posição de Platão, o qual, no oitavo livro da República, descreveu a forma democrática como "degenerada", e a manifestação de Péricles durante discurso em homenagem aos mortos da guerra do Peloponeso, momento em que teria elogiado a forma democrática, destacando a paridade de direitos civis e a meritocracia na administração do Estado ${ }^{1}$ como qualidades desse regime.

Com a concepção do governo republicano dos Estados Unidos da América, quebrou-se a ideia que permeava a democracia dos antigos de uma democracia direta, de um "governo de assembleias" que se mostrava insustentável nos grandes Estados². A "democracia dos modernos", contraposta à "democracia dos antigos", inaugurou, com o governo republicano, uma democracia representativa, "exatamente aquela forma de governo que hoje nós - convencidos de que nos grandes Estados não é possível outra democracia senão a representativa, embora em alguns casos corrigida e integrada por institutos de democracia direta" (BOBBIO, 1987, p. 150) - adotamos como modelo.

Assim, a "democracia dos modernos" nasceu a partir da concepção de que, em um Estado de vasto território e população numerosa, a única maneira de evitar um governo autocrático é por meio da instituição de um "governo de representação, que é uma forma de governo democrático corrigido, temperado ou limitado" (BOBBIO, 1987, p. 151). A forma de democracia, até então conhecida, era exercida por intermédio da participação direta nas assembleias populares; a partir do conceito de república, passou a existir a democracia na forma representativa, sistema pelo qual um reduzido número de cidadãos é eleito para representar o todo.

A crítica, que facilmente encontra-se na doutrina ${ }^{3}$ em relação à democracia representativa anterior às constituições rígidas é, de modo geral, centrada na questão da vontade majoritária, ou seja, na decisão de acordo com a vontade da maioria. Tal fato ocorre basicamente

\footnotetext{
Trecho do discurso de Péricles à honra dos mortos na guerra do Peloponeso: "Temos uma constituição que não emula as leis dos vizinhos, na medida em que servimos mais de exemplo aos outros do que de imitadores. E como ela é dirigida de modo a que os direitos civis caibam não a poucas pessoas, mas à maioria, ela é chamada democracia: diante das leis, naquilo que diz respeito aos interesses privados, a todos cabe um plano de paridade, enquanto que no que diz respeito à consideração pública na administração do Estado, cada um é escolhido conforme tenha se destacado num determinado campo, não por ser proveniente de uma dada classe social, mas sim por aquilo que vale" (BOBBIO, 1987, p. 140).

2 Grandes Estados, neste contexto, significa Estados com grande extensão territorial e população numerosa, em contraposição aos pequenos Estados, onde era possível reunir facilmente os cidadãos em uma assembleia popular.

3 Neste sentido: JULIOS-CAMPUZANO, Afonso de. Constitucionalismo em tempo de globalização. Tradução José Luís Bolzan de Morais e Valéria Ribas do Nascimento. Porto Alegre: Livraria do Advogado, 2009; FERRAJOLI, Luigi. A democracia através dos direitos: o constitucionalismo garantista como modelo teórico e como projeto político. Tradução Alexandre Araújo de Souza et al. São Paulo: Revista dos Tribunais, 2015 e BOBBIO, Norberto. Estado, governo, sociedade: por uma teoria geral da política. Tradução Marco Aurélio Nogueira. Rio de Janeiro: Paz e Terra, 1987.
} 
porque, ante as constituições flexíveis, a vontade da maioria é ilimitada e poderá assumir o potencial perigoso de servir como instrumento de dominação ou, até mesmo, de eliminação de uma minoria.

Ao analisar o Constitucionalismo francês, que surgiu com a Revolução Francesa, Afonso de Julios-Campuzano (2009, p. 24) destaca o princípio majoritário como "fragilidade"; porquanto, ao se traduzir a "onipotência da maioria" no mundo jurídico em "onipotência do legislador" elevado à condição de representante da vontade da maioria, a lei é convertida em "elemento central da produção jurídica, e o legislador é elevado à categoria de artífice da nova ordem".

No Estado de Direito, a preocupação fundamental é a limitação do poder e a tutela da liberdade dos indivíduos. Destarte, as garantias constitucionais são circunscritas a determinadas proibições, que têm como fundamento a proteção do indivíduo contra as ações do Estado; uma restrição ao poder do Estado sobre o indivíduo, tutelando basicamente os direitos de liberdade, por isso conhecido como Estado Liberal.

Em que pese o objetivo fundamental de limitar o poder mediante a submissão à lei, no Estado Liberal de Direito o modelo formal e as constituições flexíveis, desprovidas de força normativa, eram fatores que, ante a "onipotência do legislador", permitiam que a lei fosse naturalmente modificável, posto que, de acordo com essa regra, era o "legislador quem, em última instância", decidia "sobre a modificação da Constituição que, ao final", era "revestida sob a forma de uma simples lei, desprovida de mecanismos especiais de proteção" (JULIOS-CAMPUZANO, 2009, p. 14).

Tal cenário sofreu grandes transformações com a introdução do modelo de constituições rígidas e supremas, as quais passaram a ter força normativa, incluindo em seus textos princípios e direitos fundamentais. Nessa conjunção, Luigi Ferrajoli trabalha o garantismo como novo paradigma teórico geral, segundo o qual as garantias constitucionais representam "o conjunto dos limites e dos vínculos impostos a quaisquer poderes, idôneos a garantir a máxima efetividade de todos os direitos e de todas as promessas constitucionais" (FERRAJOLI, 2015, p. 31).

Em sua obra intitulada A democracia através dos Direitos: o constitucionalismo garantista como modelo teórico e como projeto político, Luigi Ferrajoli (2015) trata de um novo paradigma teórico - o paradigma constitucional -, com implicações nas ordens jurídica e democrática. Para explicar o novo paradigma, inicia discorrendo sobre três modelos teóricos ou três paradigmas do direito: o jurisprudencial, o legislativo e o constitucional.

O paradigma jurisprudencial da pré-modernidade é atribuído ao período durante o qual inexistia monopólio sobre a produção normativa; havia apenas máximas como princípios jurídicos e precedentes judiciais, os quais eram transmitidos culturalmente bem como pela jurisprudência e pela doutrina. Nesse contexto, existência e validade das normas estavam diretamente relacionadas à sua "substância ou ao seu conteúdo prescritivo" (FERRAJOLI, 2015, p. 18), ou seja, havia uma lógica interna de justiça e adequação a partir do caso concreto, característica do jusnaturalismo. 


\section{Humanos e \\ Democracia}

Já o modelo legislativo teria surgido como sucessão ao jurisprudencial, situação em que o Estado passou a ser o único legítimo produtor das normas, estabelecendo, assim, o monopólio da produção da lei, consubstanciado no princípio da legalidade atrelado à forma de produção legislativa, dando início ao juspositivismo como filosofia do direito e separando o direito da moral. De acordo com esse modelo, consolidado com base no princípio da legalidade, uma norma era posta como existente e válida a partir do exame formal, cuja análise realizada era restrita à forma da produção normativa, desconsiderando o conteúdo nessa apreciação (IPPOLITO, 2011).

Por fim, surge o novo paradigma constitucional, o qual impõe a sujeição das leis a uma constituição rígida, o que significa mudanças profundas que alteram, inclusive, a conformação do exercício do poder democrático. Com esse novo modelo teórico, foram alteradas as condições de validade das leis. No plano interno, passa a haver duas condições - a de existência e a de validade -, enquanto no plano externo também há divisão - neste caso entre justiça e validade.

As constituições rígidas, que incorporaram em seus textos direitos fundamentais e sistemas de controle da constitucionalidade, são fruto da revisão dos sistemas jurídicos instituídos após a Segunda Guerra Mundial, momento em que havia um grande abalo provocado pelas atrocidades da guerra e uma necessidade latente de ver protegidos direitos e garantias fundamentais contra um eventual regime totalitário.

No que diz respeito às garantias constitucionais, Luigi Ferrajoli (2014) esclarece que são elas que asseguram a rigidez imposta pelos princípios e direitos constitucionais sobre os poderes estatais (Legislativo, Executivo e Judiciário) e, com isso, alocam as constituições em condição de superioridade em relação às demais normas que compõem o ordenamento jurídico, ou seja, no topo da hierarquia das fontes. Essa rigidez constitucional é assegurada por duas garantias: uma primária e uma secundária. A garantia primária consiste na proibição de derrogação e impõe a obrigação de aplicação de princípios, direitos e institutos consagrados na Constituição. Por outro lado, a garantia secundária assegura o controle judicial de constitucionalidade das leis, as quais devem estar de acordo com a norma constitucional.

As alterações das condições de validade, decorrentes da efetivação das constituições rígidas como normas hierarquicamente superiores identificadas no modelo constitucional, incluem, além da já conhecida validade formal, atrelada à forma de produção legislativa, a validade substancial, ou seja, aquela que leva em consideração o conteúdo por meio da aferição da necessária coerência dos conteúdos das leis com os princípios e direitos fundamentais constitucionais (CADEMARTORI, 2007). Dessa maneira, estabeleceu-se uma distinção entre a existência diretamente relacionada ao aspecto formal de produção normativa e a validade que impõe a adequação do conteúdo das leis às disposições constitucionais.

Tais mudanças não afetam a característica monodinâmica do sistema jurídico, de modo que a existência de uma norma permanece condicionada à observância da forma estabelecida; o que muda é que, a essa conformidade formal, é acrescentada a "dimensão nomostáti$c a^{\prime \prime}$, ante a qual a norma produzida indevidamente ou, ainda, não produzida de acordo com a constituição, deve ser "removida" do ordenamento jurídico (FERRAJOLI, 2015). Esse caráter nomostático decorre do reconhecimento das garantias constitucionais como instrumento que 
impõe a todos os Poderes do Estado tanto o dever de omissão (não lesão), a exemplo dos direitos de liberdade, quanto o dever prestacional de dar efetividade a determinados direitos, como os direitos sociais.

O novo paradigma constitucional, em clara oposição ao jusnaturalismo, é apresentado por Luigi Ferrajoli (2015) como juspositivismo ampliado. A ampliação, ou complementação, consiste na extensão da subordinação de todos os Poderes, o que no velho juspositivismo se limitava à forma, e no positivismo ampliado inclui a subordinação substancial. Ou seja, além da forma, deve ser observado o conteúdo e a sua consonância com os princípios e os direitos fundamentais positivados na Constituição. ${ }^{4}$

Nesse cenário, a jurisdição é subordinada à legislação, e esta, por sua vez, é subordinada à Constituição, tanto no seu aspecto formal quanto no seu aspecto substancial. A partir dessas premissas de subordinação formal e substancial, Luigi Ferrajoli (2015) sustenta que o juspositivismo ampliado é unido ao sistema político por dois eixos, sendo um estrutural, ligado ao Estado de Direito fundado no princípio da legalidade, e o outro instrumental, ligado à democracia, em que forma e conteúdo são relevantes na produção normativa.

O eixo estrutural tem sua base no princípio da legalidade, o qual, a partir do novo paradigma constitucional, passa a ter uma configuração mais abrangente do que aquela que tinha no Estado Legislativo do governo per leges, caracterizado pelas leis gerais e abstratas. A partir desse novo contexto de governo sub leges, o princípio da legalidade deve ser compreendido como dois princípios, que são ao mesmo tempo distintos e conexos: o da "mera legalidade", que possui sentido "lato, fraco ou formal", e o da "legalidade estrita", cujo sentido é "estrito, forte ou substancial" (FERRAJOLI, 2015, p. 32).

O princípio da "mera legalidade", cujo sentido é lato, fraco ou formal, está relacionado à existência do direito no seu aspecto formal, ou seja, é análogo ao princípio da positividade, ${ }^{5}$ forma já conhecida antes do constitucionalismo, presente até mesmo nos regimes totalitários. Significa que todo poder somente será concedido por lei e na exata forma da lei (CADEMARTORI, 2007, p. 13).

Diferente é a aplicação do princípio da "legalidade estrita", que ultrapassa o aspecto lato, fraco ou formal e avança sobre o conteúdo como forma de garantia, situação em que o sentido passa a ser estrito, forte ou substancial, colocando a lei como limitadora do poder ao estabelecer, além da forma, aquilo que pode ou não ser definido por lei de hierarquia inferior, o que significa uma inversão importante na medida em que o poder deixa de dispor

\footnotetext{
Susana Pazzolo, na obra Neoconstitucionalismo(s), organizada por Miguel Carbonal, ao analisar as teses neoconstitucionalistas de interpretação moral da constituição, alerta que "el imperialismo de la moral, típico del neoconstitucionalismo, no me parece que haga nada más que elevar um nuevo "rei" por encima del Derecho, y quien tuviera la "sapiência" para acceder al "conocimiento moral podría transformarse en un déspota mucho más peligroso que la terrana autoridade política" (2009, p. 210).

5 Na forma do princípio da mera legalidade, ligado à positividade, "é direito tudo e somente o que é posto ou produzido por intermédio do exercício dos poderes conferidos pela lei e nas formas estabelecidas" (FERRAJOLI, 2015, p. 32).
} 


\section{Humanos e}

Democracia

livremente do direito e passa a ser limitado pelo direito (CADEMARTORI, 2007, p. 13-15). Sobre esse aspecto, além do exame da existência do direito, acresceu-se o exame da validade substancial. $^{6}$

Daniela Mesquita Leutchuk Cademartori e Sérgio Cademartori (2006, p. 150), ao analisarem o modelo de Estado que passou a existir a partir do Constitucionalismo, baseados na concepção de Estado de Direito da obra Derecho y razón, de Luigi Ferrajoli , fazem uma síntese em que abordam o plano formal e o plano substancial como "fontes de legitimação" aos quais são correlatos "dois modelos de legalidade: legalidade em sentido amplo (mera legalidade), segundo a qual a lei é condicionante, e legalidade em sentido estrito (legalidade estrita), por força da qual a lei se encontra condicionada".

O eixo instrumental liga a democracia ao positivismo jurídico, cuja ressalva importante, feita por Luigi Ferrajoli (2015), esclarece que o paradigma constitucional é um modelo teórico, e como tal não é o bastante para garantir conteúdos democráticos, posto que uma constituição compreende um conjunto de normas de cunho hierárquico, sem assegurar que sejam necessariamente democráticas. ${ }^{7}$ São compreendidos como conteúdos democráticos normas positivadas que assegurem direitos imprescindíveis aos cidadãos, ou seja, o dever ser do direito.

Apenas com a inclusão de normas formais e substanciais na Constituição e, devido "ao consequente caráter artificial de umas e de outras, foi possível inserir, nos dois paradigmas do Estado de Direito, formas e conteúdos democráticos" (FERRAJOLI, 2015, p. 35). No positivismo jurídico ampliado está presente, além do ser condizente com a forma de produção normativa, o dever ser do direito, aquilo que deve ser observado como conteúdo a ser assegurado.

O ser indica a legitimidade formal da produção legislativa, definindo as condições de validade afetas à forma de governo definidas e aferidas a partir das regras de quem pode decidir e como pode decidir. O dever ser indica a legitimidade substancial da norma e a conformidade do conteúdo com o texto constitucional, o qual limita o que pode ou não ser decidido (CADEMARTORI; CADEMARTORI, 2006, p. 151).

A inclusão de princípios e direitos fundamentais no texto constitucional, elevada à condição de norma suprema com força normativa, imposta indistintamente a todos os Poderes, inclusive ao Legislativo, o qual deve observar não apenas a forma, mas, sobretudo, o conteúdo, retirou do mundo jurídico a presunção de legitimidade da lei fundada no processo legislativo formal. Eis que podem existir lacunas e antinomias (CADEMARTORI, 2007, p. 105), as quais são examinadas no plano do dever ser, o que significa que haverá um conflito entre

\footnotetext{
Considerando o princípio da legalidade sobre o viés da "mera legalidade" associado ao da "legalidade substancial", resta clara a submissão de todos os poderes, inclusive o legislativo, aos princípios e direitos fundamentais positivados na constituição, o que significa a extinção da "última forma do governo dos homens, que no antigo paradigma legislativo se manifestava na onipotência do legislador" (FERRAJOLI, 2015, p. 34). Sobre o governo dos homens, quando Bobbio fala da Antiguidade e sobre a pergunta que havia no sentido de saber qual seria o melhor governo, o dos homens ou o das leis, busca uma citação bastante elucidativa em Platão, o qual, ao distinguir um governo bom de um governo mau, discorre que: "Onde a lei é súdita dos governantes e privada de autoridade, vejo pronta a ruína da cidade [do Estado]; e onde, ao contrário, a lei é senhora dos governantes e os governantes seus escravos, vejo a salvação da cidade e a acumulação nela de todos os bens que os deuses costumam dar às cidades" (PLATÃO apud BOBBIO 1987, p. 96).

7 Luigi Ferrajoli destaca que, assim como podem existir leis antiliberais e antidemocráticas, também pode haver constituições com essas características, ou seja, constituições que não sejam democráticas (2015, p. 35).
} 
normas de hierarquias diferentes quando uma norma inferior não observar as condições de validade substancial, e ao ignorar ou ferir determinados valores positivados, por exemplo, os relativos à igualdade, o que, por sua vez, autoriza o controle do dever ser da atividade legislativa por parte do Poder Judiciário.

Um exemplo que bem ilustra a atuação do Judiciário pode ser extraído do julgamento do Recurso Extraordinário 586.224 SP, realizado pelo Pleno do Supremo Tribunal Federal, em que o relator ministro Luiz Fux, ao discorrer acerca da expansão da atuação do Poder Judiciário ante a força de aplicação imediata dos direitos fundamentais e o caráter de exigibilidade destes, faz referência expressa à teoria garantista nos seguintes termos: "Como leciona Luigi Ferrajoli, com a finalidade de guardar a Constituição, esta Corte jamais poderá se furtar de garantir um direito fundamental, sob pena de negar-lhe existência" (RE 586.224 SP, Plenário STF, 05.03.2015).

Essa nova concepção de controle sobre o dever ser normativo levou Luigi Ferrajoli a trabalhar um novo paradigma teórico de democracia, advindo do constitucionalismo rígido, com separação de validade e vigência. O jurista sustenta a articulação da noção de democracia em dimensões, mais especificamente em quatro dimensões, de acordo com os direitos fundamentais positivados, divididos, igualmente, em quatro grupos.

\section{OS DIREITOS FUNDAMENTAIS E O MODELO DE DEMOCRACIA QUADRIDIMENSIONAL}

Com a adoção do modelo de constituições rígidas que asseguram direitos e garantias, a mudança do paradigma, seja no direito, seja na democracia, está na distinção entre o ser e o dever ser, em que a vigência tem relação direta com o ser, isto é, com a forma de produção da norma, enquanto a validade é relacionada ao dever ser constitucional, ou seja, a validade substancial a partir da adequação aos direitos e às garantias constitucionais (CONPETTI NETO, 2013). Sob o viés do paradigma constitucional e da separação entre vigência e validade, há um avanço no sentido de que passou a existir, além do exame da validade formal, já existente no Estado de Direito, o exame sob a validade substancial, o que permite afirmar que é possível a existência de leis inválidas.

Luigi Ferrajoli (2015, p. 55), partindo das premissas de que na democracia formal a conformidade é aferida por meio dos critérios de "quem" e "como", elementos que estão relacionados à forma de governo, e de que na democracia substancial o critério para aferição é o de "que coisa", sendo este, então, conexo à substância daquilo que é decidido, de modo que seja resguardada a coerência com os direitos e princípios constitucionais, propõe uma noção de democracia quadridimensional. Essas quatro dimensões da democracia, para o autor, dividem-se em duas formais, também classificadas como secundárias ou instrumentais, e duas substanciais, qualificadas como primárias ou finais. São elas: política, civil de aspecto formal, civil de aspecto liberal e social de aspecto substancial. Essas quatro dimensões representam, respectivamente, os direitos fundamentais: políticos, civis, de liberdade e sociais (FERRAJOLI, 2015).

A dimensão política, primeira dimensão formal de esfera pública, é conexa com os direitos políticos e o sistema representativo, ou seja, com o sufrágio universal e o princípio da maioria, já conhecidos no Estado de Direito, tratando-se do controle de quem e como. 


\section{Humanos e \\ Democracia}

Esse controle não é o bastante ante o paradigma constitucional, uma vez que representa apenas uma das condicionantes de validade de uma lei, bem como apenas um sentido de democracia.

A segunda dimensão é a dimensão civil, também formal, mas de esfera privada, em que igualmente se dá o exame de quem e como, só que, neste caso, relacionado aos direitos civis voltados a assegurar a autonomia dos cidadãos detentores de capacidade de agir, isto é, de pactuar negócios, como celebrar contratos entre privados, constituindo "direitos-poderes exercidos por intermédio de atos que interferem na liberdade dos outros, por causa dos efeitos obrigatórios por eles produzidos" (FERRAJOLI, 2015, p. 57).

A dimensão liberal, terceira dimensão da democracia, segundo a teoria garantista, assim como a quarta, é uma dimensão substancial. Nesse contexto, as decisões são analisadas sob a ótica de conteúdo ou substância, isto é, que coisa. A dimensão substancial é "delimitada pelos limites e vínculos jurídicos, de substância ou de conteúdo, impostos aos poderes políticos majoritários" (FERRAJOLI, 2015, p. 11).

A limitação do princípio da maioria, ${ }^{8}$ característica da dimensão substancial da democracia, eleva princípios e direitos positivados na constituição ao patamar de garantia, de modo que não possam ser eliminados nem sonegados. Constitui, assim, o que Luigi Ferrajoli (2015, p. 11) conceituou como "esfera do não decidivel", aquilo que está assegurado no texto constitucional sobre o que "nenhuma maioria pode validamente decidir, isto é, a violação ou a restrição dos direitos de liberdade, e aquilo que nenhuma maioria pode legitimamente deixar de decidir, isto é, a satisfação dos direitos sociais constitucionalmente estabelecidos".

Tendo presentes essas máximas, percebe-se facilmente que o princípio da maioria, no modelo garantista, é limitado tanto pela esfera do indecidivel quanto pela esfera do indecidível que não, o que significa limites impostos à regra da maioria, quer dizer, à existência de garantias constitucionais capazes de assegurar que a maioria, em nenhuma hipótese, poderá decidir de modo a abolir direitos de uma minoria, seja na forma de garantia negativa (ex.: direito de liberdade), seja na forma de garantia positiva (ex.: direito à saúde ${ }^{9}$ ).

O que diferencia as duas dimensões substanciais é que, na terceira dimensão, o exame sobre conteúdo ou substância das decisões ocorre sob o enfoque dos direitos de liberdade positivados na Constituição. São os direitos fundamentais relacionados à liberdade e à autonomia dos indivíduos a partir dos quais são vedadas determinadas decisões, isto é, são direitos protegidos, contemplados na esfera do indecidivel. Enquanto isso, a dimensão social, quarta da classificação quadridimensional e segunda substancial, é composta pelos direitos sociais positivados em uma constituição como "expectativas positivas". São os direitos que possuem

\footnotetext{
8 Adriano de Bortoli, ao discorrer sobre a redefinição do conceito de democracia a partir do garantismo, fala que o "ponto central da definição garantista da democracia é a relativização da utilização da regra segundo a qual a maioria, direta ou indiretamente, decide sobre tudo". Aborda o fato de que nem sobre tudo é possível decidir, da mesma forma que "nem sobre tudo se pode deixar de decidir, nem por maioria", de modo que a regra da maioria se aplicará apenas para o "restante das decisões que não estejam limitadas substancial e democraticamente" (2008, p. 5.995).

9 Francisco José Rodrigues de Oliveira Neto, ao discorrer acerca das transformações provocadas pelo constitucionalismo, aborda a questão que afeta a ideia de democracia: "Ao se adotar a rigidez como característica principal de uma Constituição, não se poderá mais admitir que a simples maioria pudesse determinar a supressão de qualquer direito, evidenciando-se assim a necessidade de respeito aos direitos de minoria" (2012, p. 1.903).
} 
encargo obrigacional no sentido de impor à esfera pública deveres de agir; são aqueles direitos que devem ser efetivados e, por isso, são integrantes da esfera do não decidível que não, eis que é proibido decidir não agir (FERRAJOLI, 2015, p. 58).

A Constituição, elevada à condição de norma suprema com um forte sistema de garantias, produz reflexos significativos sobre a concepção de democracia, como sintetiza Luigi Ferrajoli: "O princípio da democracia política, relativo a quem decide, é, em suma, subordinado aos princípios da democracia social relativos ao que não é lícito decidir e ao que não é lícito não decidir" (2006, p. 788).

Daniela Cademartori e Sérgio Cademartori (2015, p. 233), ao discorrem acerca do modelo quadridimensional da democracia, sintetizam, de maneira muito elucidativa, a teoria de Luigi Ferrajoli ao classificarem as duas primeiras dimensões de ordem formal, relacionadas à titularidade de quem decide e ao procedimento de como se decide, em "democracia política e democracia civil". Quanto as duas dimensões substanciais, ambas afetas ao conteúdo, ou seja, ao que se decide, os autores classificam em "democracia liberal ou liberal-democracia e democracia social ou socialdemocracia".

No Brasil, a Constituição Federal de 1988 possui essa característica de constituição rígida, elevada à condição de norma suprema, contendo diversos princípios e direitos fundamentais positivados, constituindo um campo protegido por garantias negativas e assegurado por garantias positivas, cujas repercussões se fazem sentir, também, sobre o exercício da democracia.

\section{PARTICIPAÇÃO POPULAR NO BRASIL SOB A ÓTICA DO NOVO PARADIGMA CONSTITUCIONAL}

No texto constitucional brasileiro, como primeira disposição, é declarado que o Brasil "constitui-se em Estado Democrático de Direito", cujos fundamentos básicos são a soberania, a cidadania, a dignidade da pessoa humana, os valores sociais do trabalho e da livre-iniciativa e o pluralismo político. Dispõe, ainda, que todo poder emana do povo na forma representativa ou direta. ${ }^{10}$

O princípio democrático positivado na Constituição Brasileira assegura o exercício da democracia por todos os cidadãos em igualdades de condições, tanto na sua forma procedimental, por meio do sufrágio universal, quanto na sua forma direta, posto que, em relação a esta, alguns instrumentos são igualmente positivados no texto constitucional.

O exercício da democracia na sua forma direta significa a possibilidade de participação direta dos cidadãos tanto nos procedimentos afeitos às tomadas de decisão quanto no exercício do controle do poder. José Joaquim Gomes Canotilho (2003, p. 290) descreve o princípio

\footnotetext{
${ }^{10}$ Art. 1ํ A República Federativa do Brasil, formada pela união indissolúvel dos Estados e Municípios e do Distrito Federal, constitui-se em Estado Democrático de Direito e tem como fundamentos:

I- a soberania;

II - a cidadania;

III - a dignidade da pessoa humana;

IV - os valores sociais do trabalho e da livre-iniciativa;

$\checkmark$ - o pluralismo político.

Parágrafo único. Todo o poder emana do povo, que o exerce por meio de representantes eleitos ou diretamente nos termos desta Constituição.
} 


\section{Humanos e \\ Democracia}

democrático como um "princípio de organização", tanto no que diz respeito à titularidade quanto no que concerne ao exercício do poder, de tal modo que "o poder político é constituído, legitimado e controlado por cidadãos (povo), igualmente legitimados para participarem no processo de organização da forma de Estado e de governo".

A participação popular, seja como instrumento de controle do Poder, seja na forma de participação ativa nos processos de tomadas de decisão, uma vez interpretada pelo viés da teoria garantista, deve ser vista como importante instrumento constitucionalmente positivado. Essa participação cidadã, a partir do paradigma constitucional, também está submetida aos princípios e direitos fundamentais tutelados, independente de se tratar do interesse de uma maioria ou de uma minoria, e deve, sim, estar em sintonia tanto no aspecto formal quanto no substancial com a norma constitucional.

Como abordado anteriormente, também ao cidadão aplica-se a regra da esfera do indecidível e do indecidível que não, a qual não pode ser alterada nem mesmo pela vontade unânime. ${ }^{11}$ Tanto no que diz respeito à democracia representativa quanto ao que está afeto à democracia participativa, os direitos e as garantias assegurados constitucionalmente, em um ordenamento jurídico, são limitadores dos Poderes na medida em que formam uma esfera em relação à qual, sob o manto da proteção constitucional, não pode haver ingerência, nem mesmo pela vontade da maioria do povo ou pela totalidade do povo. Esse espaço de proteção integral da norma constitucional sobre determinados direitos e garantias, que no Brasil é conhecido por cláusulas pétreas, é denominado, por Luigi Ferrajoli (2015, p. 58), como esfera do indecidível, enquanto Ernesto Garzón Valdés (1989, p. 209) o chama de "el coto vedado".

Adotando o modelo quadridimensional da democracia, percebe-se que o exercício da democracia representativa - aquela que se dá por meio do sufrágio universal e do princípio da maioria - enquadra-se na dimensão política, isto é, na primeira dimensão formal. Outros aspectos, contudo, precisam ser considerados, e pelo menos em um deles, na dimensão substancial dos direitos sociais, a participação popular de forma direta pode ser um elemento importante.

No artigo 60 da Constituição Federal Brasileira de 1988, foram positivados os seguintes direitos sociais: a educação, a saúde, o trabalho, o lazer, a segurança, a previdência social, a proteção à maternidade e à infância e a assistência aos desamparados. No ano de 2000, por meio da Emenda à Constituição no 26, foi acrescentado o direito à moradia. Outro direito social - o direito à alimentação - foi acrescido, em 2010, por intermédio da Emenda no 64, e, recentemente, após inúmeras e expressivas manifestações populares relacionadas ao transporte público, o "passe livre" foi inserido, com a Emenda no 90, como direito ao transporte na relação de direitos sociais positivados.

\footnotetext{
${ }^{11}$ Luigi Ferrajoli afirma que existem duas falácias ideológicas sobre a concepção apenas formal da democracia: "A ideia de que o poder do povo seja bom e justo e o autogoverno que, por estas formas, resultaria garantido". Especificamente sobre autogoverno (autonomia e autodeterminação) popular, visto como a "liberdade positiva do povo de não estar sujeito a outras decisões que não sejam deliberadas por eles mesmos", segundo o autor, somente existiria em uma democracia direta em que todas as decisões fossem unânimes, o que seria uma destruição muito mais grave do espírito da democracia, posto que o que caracteriza democracia é muito mais o livre-dissenso que o livre-consenso (2015, p. 39-43).
} 
Especificamente no que concerne aos direitos sociais, aqueles sobre os quais é imposto um dever de agir com vistas à sua efetividade, tem-se, segundo a teoria garantista, na dimensão social da democracia, um dever de agir sobre o que não é possível decidir, uma vez que são direitos que compõem a esfera do indecidivel, mais precisamente a esfera do não decidível que não.

Acerca da esfera do indecidível, no que diz respeito aos direitos sociais, é preciso registrar que estes formam "a esfera do indecidível que não, determinada pelo conjunto dos direitos sociais, os quais impõem a obrigação, enquanto expectativas positivas, das decisões destinadas a satisfazê-los". Isso significa que só é decidível, ou seja, somente pode ser objeto da discricionariedade do administrador público, da disponibilidade privada, de decisão por maioria, de liberdade de empresa e de autodeterminação econômica, aquilo que não está contido na esfera do indecidivel (FERRAJOLI, 2015, p. 58).

Como se vê, os direitos sociais positivados são mais que uma mera expectativa de direito a ser concretizado; são, em verdade, mandamentos constitucionais que devem ser efetivados, observada a consonância tanto no que se refere à forma quanto ao conteúdo, ou seja, à esfera substancial. Esse dever de agir é imposto a todos os Poderes, inclusive ao Legislativo, e, de igual sorte, naquilo que é vedado decidir que não; nem mesmo a decisão amparada no princípio da maioria é admissível.

Em relação à instituição e à efetivação dos direitos sociais constitucionalmente tutelados, a participação popular ativa pode ocorrer e é salutar que se faça presente nos processos de tomadas de decisão, em que há liberdade para decidir, isto é, quando existe um espaço que não esteja coberto pela esfera do indecidível.

A Constituição Federal, em alguns dispositivos, faz referência expressa sobre a participação cidadã, seja como diretriz, seja como objetivo ou até mesmo na fiscalização de alguns processos referentes a direitos sociais, como os artigos 79 e 82, que preveem a participação da sociedade civil na gestão dos Fundos de Erradicação da Pobreza (BRASIL, 1988).

Dois outros dispositivos, estes relacionados ao direito ao trabalho, trazem consigo mandamentos de processos participativos. São o artigo 10, que assegura a participação de trabalhadores e empregadores nos órgãos públicos colegiados, em que seus interesses sejam profissionais, sejam previdenciários e estejam em processo de discussão ou deliberação, e o artigo 187, que prevê a participação efetiva de produtores, trabalhadores rurais e toda a cadeia de produção no planejamento e na execução da política agrícola (BRASIL, 1988).

No que diz respeito ao direito à seguridade social, o artigo 194, parágrafo único, inciso VII, incluído por meio da Emenda Constitucional no 20, dispõe sobre a gestão quadripartite, incluindo, nos órgãos colegiados, trabalhadores, empregados, aposentados e representantes do governo, de modo a assegurar o caráter democrático e descentralizado da administração (BRASIL, 1988).

De igual sorte, ao tratar do direito à saúde, conforme previsto no artigo 198, inciso II, a participação da comunidade está definida como uma das diretrizes. Não é diferente quando, por meio do artigo 204, inciso II, a Constituição Federal dispõe acerca da participação popular na definição das políticas públicas e no exercício do controle das ações na área da assistência 


\section{Humanos e \\ Democracia}

social. E, ainda, não menos importante, sobre o direito social à educação, no artigo 206, inciso VI, a participação popular está prevista como princípio à gestão democrática do ensino público (BRASIL, 1988).

Outros dispositivos da Constituição Brasileira fazem referência à participação popular, como o artigo 58, § 2으. inciso II, que prevê a realização de audiências públicas com entidades da sociedade civil por parte das Comissões Parlamentares. No artigo 216-A, acrescido pela Emenda Constitucional no 71 de 2012, no parágrafo único, inciso X, a participação e o controle popular na democratização dos processos decisórios constam definidos como um dos princípios do Sistema Nacional de Cultura (BRASIL, 2012).

Em todos esses dispositivos constitucionais supramencionados, identificam-se objetivos e diretrizes voltados à inserção do cidadão nos processos de decisão. Tanto no que se é possível decidir (não limitados pela esfera do indecidível) quanto no que se é obrigado a decidir (esfera do indecidível que não), a contribuição popular pode ser um elemento rico na construção da efetividade dos direitos sociais positivados. Diogo de Figueiredo Moreira Neto (2014), respeitado jurista brasileiro, ao discorrer sobre relações entre Poderes e democracia, enfatiza a importância da participação popular direta em processos de formulação de políticas públicas como medida de ampliação da própria legitimidade das decisões políticas.

A participação popular ativa, à medida que aproxima a comunidade dos centros de decisão, permite aos poderes públicos disporem de visões diversificadas acerca de determinado tema ou situação posta, podendo, assim, examinar, sob diversos ângulos, desde a opinião da maioria até a da minoria, dos mais favorecidos e dos menos favorecidos, dos mais esclarecidos e dos menos esclarecidos, o que pode representar um ganho significativo, seja na definição de políticas públicas ou até mesmo nos processos de normatização, tendo sempre presentes os princípios e direitos fundamentais assegurados. Conforme ensina José Joaquim Gomes Canotilho (2003, p. 288), “o princípio democrático implica democracia participativa, isto é, a estruturação de processos que ofereçam aos cidadãos efectivas possibilidades de aprender a democracia".

Ainda sobre a participação social nos processos de tomadas de decisão, mas não necessariamente relacionados aos direitos sociais, o artigo 14 da Constituição dispõe sobre a soberania popular e seu exercício em igualdade de condições por meio do sufrágio universal e pelo voto direto e secreto, bem como por meio de plebiscito, referendo e iniciativa popular, regulamentados pela Lei no 9.709, de 18 de novembro de 1998 (BRASIL, 1998). No caso do plebiscito e do referendo, a participação popular é deliberativa, uma vez que, sempre que houver necessidade de decidir sobre alguma matéria de acentuada relevância de natureza constitucional, legislativa ou administrativa, deve ser consultada a população e decidido pelo princípio da maioria. A diferença entre ambos está no fato de que o primeiro deve ser realizado antes de elaborado o ato legislativo ou administrativo, enquanto o segundo é posterior à elaboração. Assim, a decisão será no sentido de ratificar ou rejeitar. Já a iniciativa popular consiste na faculdade a qual a população dispõe de apresentar projeto de lei à Câmara dos Deputados, de acordo com as regras previstas na Lei no 9.709, de 18 de novembro de 1998 (BRASIL, 1998). 
No Brasil, ainda há muito a ser feito no tocante aos direitos sociais na busca da efetividade dessas garantias. A definição de políticas públicas ${ }^{12}$ e a efetivação dos direitos, na maioria das vezes, não depende de lei, e sim de ação pública, ou seja, é uma atividade de gestão pública. É nesse espaço da dimensão social da teoria garantista que o exercício da democracia, por meio da participação direta do cidadão, deve se fazer presente.

Entre os estudiosos do direito administrativo brasileiro, muitos falam da constitucionalização e da importância da participação cidadã e do exercício da democracia para legitimar os atos dos gestores públicos ${ }^{13}$. Consoante Diogo Moreira Neto (2007), entre democracia e legitimidade existe uma relação direta. $\mathrm{O}$ autor destaca que a legalidade consiste no limite determinado pela lei, estabelecido na ordem jurídica com o Estado de Direito, enquanto no Estado Democrático, de formação pluriclasse, a legitimidade é o limite imposto, "dependente do consenso sócio-político" (MOREIRA NETO, 2007, p. 40).

Já Fernando José Rodrigues de Oliveira Neto (2012, p. 1.932) destaca que, após as mudanças efetivadas na ordem democrática, as quais levaram à ampliação da submissão do legislativo à constituição além dos aspectos afetos à formalidade, passando a abarcar também o dever de conformidade de seu conteúdo, restaram "duas possibilidades de atuação: 1) a inércia ou 2) o desenho legislativo para implementar direitos, já que a retirada é inviável em um quadro de respeito à ordem constitucional". Segundo o autor, entre essas possibilidades a mais comum é a inércia ante ao que a alternativa social é na "pressão popular", no sentido de fazer com que o Legislativo atue de forma a efetivar os direitos.

Entende-se que, tendo o constitucionalismo como paradigma e considerando a democracia quadridimensional, no que concerne especificamente à dimensão social que afeta diretamente os direitos sociais positivados, a participação popular deve se dar de duas formas: no que estiver sobre o manto da esfera do indicidível, a atuação deve se dar na forma de fiscalização, e no que estiver na esfera do decidível, como a definição de políticas públicas, por exemplo, deve haver participação direta dos cidadãos, não no modo de decisão da maioria, mas de participação como contribuição no debate, como elemento de coleta de contribuição, engajamento social e maior aceitação. ${ }^{14}$

\footnotetext{
${ }^{12}$ Sobre o conceito de políticas públicas no Brasil, José Sérgio da Silva Cristóvam (2011, p. 55) é bastante elucidativo ao dissertar que "as políticas públicas podem ser entendidas como o conjunto de planos e programas de ação governamental voltados à intervenção no domínio social, por meio dos quais são traçadas as diretrizes e metas a serem fomentadas pelo Estado, sobretudo na concretização dos objetivos e direitos fundamentais insculpidos na Constituição". O autor ainda destaca que "no Estado constitucional de direito, a função fundamental da Administração Pública é a concretização dos direitos fundamentais positivos, por meio de políticas públicas gestadas no seio do Poder Legislativo ou pela própria Administração, políticas estas orientadas pelos princípios e regras dispostos na Constituição" (2011, p. 56).

${ }^{13}$ Cláudio Mastrangelo (2005, p. 20), em sua obra intitulada Agências Reguladoras e Participação Popular, analisa com profundidade a participação popular como elemento de legitimação das decisões das agências reguladoras no Brasil. O parágrafo que ora se destaca ilustra muito bem seu posicionamento: "No âmbito da Administração Pública, o prestigiamento da participação popular coincide com o alvorecer de um novo tempo, ainda não percebido por muitos, mas que introduz concepção moderna, no sentido de ensejar à cidadania uma posição ativa nas tomadas de decisão e no próprio controle sobre suas ações. A essa altura, o destinatário deixa de ser espectador e mero alvo para se constituir em protagonista, assumindo posição interativa com a Administração Pública".

${ }^{14}$ Gustavo Binenbojm (2005, p. 15), em Agências Reguladoras Independentes e Democracia no Brasil, destaca a importância da participação popular como mecanismo de legitimação das decisões pelo procedimento, situação em que defende que "os mecanismos fundamentais de participação e controle social sobre a atividade administrativa são as audiências públicas, as consultas públicas e os conselhos consultivos".
} 


\section{Humanos e \\ Democracia}

\section{CONSIDERAÇÕES FINAIS}

No Estado de Direito Liberal, o conceito de garantias tem conteúdo diverso do que possui no Estado Constitucional de Direito. Sob a égide do Estado de Direito, a concepção de garantia restringia-se ao aspecto formal, à pura submissão da lei, conhecido como o império da lei, desprovido de qualquer exame de conteúdo.

O exame da legalidade, quanto à forma, mantém como base o Estado Constitucional de Direito. O princípio da legalidade, todavia, é ampliado, indo além do mero aspecto formal, adentrando no aspecto substancial (conteúdo) e impondo a subordinação de toda produção normativa à Constituição, seja no aspecto formal, seja no seu conteúdo material.

O então império da lei é aprimorado no Estado Constitucional de Direito, no qual passa a existir a supremacia da Constituição rígida, cujos princípios e direitos fundamentais vinculam todos os Poderes. Essa submissão à Constituição vai além do aspecto formal: tem alcance material, especialmente no que se refere aos direitos fundamentais consagrados.

Os direitos fundamentais, como garantias, a partir do Estado Constitucional de Direito, deixam de tratar apenas de assegurar um direito negativo, de não agir, no resguardo do direito de liberdade. Também passam a ser parte das garantias os direitos sociais, o que significa uma ampliação do antigo Estado de Direito, incluindo o dever de agir na promoção e na concretização desses direitos sociais constitucionalmente tutelados, de modo que o texto constitucional, com força normativa, passa a funcionar como limitador de poder e garantidor de direitos.

Aqui, sobressai a importância de que sejam assegurados tanto a forma quanto os conteúdos democráticos como elementos limitadores do princípio da maioria, bem como dos atos de todos os Poderes, evitando, com isso, a abertura de espaço para a instalação de regimes antidemocráticos, como os já registrados ao longo da história.

A Constituição Brasileira de 1988 expressamente declara o Brasil como um Estado Democrático de Direito, cujo exercício da democracia é assegurado tanto na forma representativa quanto na direta. A partir do novo paradigma constitucional e da dimensão quadridimensional da democracia, a participação popular na forma direta ganha papel relevante nos processos de efetivação dos direitos sociais. A inclusão do cidadão nos processos de efetivação dos direitos sociais tem o potencial de promover a cidadania, de dar voz às minorias, de aproximar os centros de decisão das realidades locais - muitas vezes desconhecidas - e agregar legitimidade às decisões.

A inserção do cidadão de modo ativo nos processos normativos, como aqueles que conduzem à definição e/ou à instituição de políticas públicas, além de estar em consonância com o exercício da democracia, tem o potencial de assegurar a validade substancial, isto é, do conteúdo, e, com isso, assegurar a constitucionalidade tanto formal quanto substancial, garantindo, assim, a efetividade dos direitos. 


\section{REFERÊNCIAS}

BINENBOJM, Gustavo. Agências Reguladoras Independentes e Democracia no Brasil. Revista Eletrônica de Direito Administrativo Econômico, n. 3, p. 1-20, ago./set./out. 2005. Disponível em: http://www.direitodoestado.com/ revista/redae-3-agosto-2005-gustavo\%20binenbojm.pdf. Acesso em: 20 jun. 2016.

BOBBIO, Norberto. Estado, governo, sociedade: por uma teoria geral da política. Tradução Marco Aurélio Nogueira. Rio de Janeiro: Paz e Terra, 1987.

BORTOLI, Adriano de. Garantismo Jurídico, Estado Constitucional de Direito e Administração Pública. CONGRESSO NACIONAL DO CONPEDI, 16., 2008, Florianópolis. Anais [...]. Florianópolis: Fundação Boiteux, 2008. p. 5.2826.010. Disponível em: https://s3.amazonaws.com/conpedi2/anteriores/XVI+Congresso+Nacional+-+Belo+Horizonte+(15\%2C+16+e+17+de+novembro+de+2007).pdf. Acesso em: 13 out. 2015.

BRASIL. Constituição da República Federativa do Brasil de 1988. Disponível em: http://www.planalto.gov.br/ccivil_03/constituicao/constituicaocompilado.htm. Acesso em: 11 ago. 2013.

BRASIL. Lei no 9.709, de 18 de novembro de 1998. Regulamenta a execução do disposto nos incisos I, II e III do art. 14 da Constituição Federal. Disponível em: http://www.planalto.gov.br/ccivil_03/leis/19709.htm. Acesso em: 24 maio 2016.

BRASIL. Emenda Constitucional no 71, de 29 de novembro de 2012. Acrescenta o art. 216-A à Constituição Federal para instituir o Sistema Nacional de Cultura. Disponível em: http://www.planalto.gov.br/ccivil_03/constituicao/Emendas/Emc/emc 71.htm. Acesso em: 13 out. 2015.

BRASIL. Recurso Extraordinário 586.224 SP, Brasil. Supremo Tribunal Federal. Recorrentes: Estado de São Paulo e Sindicato da Indústria da Fabricação do Álcool do Estado de São Paulo - Sifaesp. Recorridos: Câmara Municipal de Paulina e Município de Paulina. Relator ministro Luiz Fux. Julgamento 5.3.2015. Disponível em: http://redir. stf.jus.br/paginadorpub/paginador.jsp?docTP=TP\&doclD=8399039. Acesso em: 24 maio 2016.

CADEMARTORI, Daniela Mesquita Leutchuk de, CADEMARTORI, Sérgio. A relação entre Estado de Direito e democracia no pensamento de Bobbio e Ferrajoli. Revista Sequência, UFSC, no 53, p. 145-162, Florianópolis, dez. 2006. Disponível em https://periodicos.ufsc.br/index.php/sequencia/article/view/15097. Acesso em: 13 out. 2015.

CADEMARTORI, Daniela Mesquita Leutchuk de, CADEMARTORI, Sérgio. Democracia formal, substancial e ambiental: a configuração de um debate. CONGRESSO NACIONAL DO CONPEDI, 24., 2015, Belo Horizonte. Anais [...]. Belo Horizonte: UFS, 2015. Disponível em: http://www.conpedi.org.br/publicacoes/c178h0tg/2g6i4xpi/Xr87133g9jUf5FGW.pdf. Acesso em: 25 maio 2016.

CADEMARTORI, Sérgio. Estado de Direito e Legitimidade. 2. ed. Campinas: Millennium Editora, 2007.

CANOTILHO, José Joaquim Gomes. Direito Constitucional e Teoria da Constituição. 7. ed. Coimbra: Edições Almeida, 2003.

CRISTÓVAM, José Sérgio da Silva. Direitos sociais e controle jurisdicional de políticas públicas: uma abordagem a partir dos contornos do estado constitucional de direito. Revista da Escola Superior da Magistratura do Estado de Santa Catarina, v. 18, n. 24, 2011. Disponível em: http://www.revista.esmesc.org.br/re/article/view/23/29. Acesso em: 7 nov. 2015.

CONPETTI NETO, Alfredo. O paradigma constitucional garantista em Luigi Ferrajoli: a evolução do constitucionalismo político para o constitucionalismo jurídico. Revista de Direitos Fundamentais e Democracia. Curitiba, v. 14, n. 14, p. 409-241, jul./dez. 2013.

FERRAJOLI, Luigi. Direito e razão: Teoria do Garantismo Penal. Tradução Ana Paula Zomer Sica et al. 2. ed. São Paulo: Revista dos Tribunais, 2006.

FERRAJOLI, Luigi. Poderes selvagens: a crise da democracia italiana. Tradução Alexandre Araújo Souza. São Paulo: Saraiva, 2014.

FERRAJOLI, Luigi. A democracia através dos direitos: o constitucionalismo garantista como modelo teórico e como projeto político. Tradução Alexandre Araújo de Souza et al. São Paulo: Revista dos Tribunais, 2015.

FERRAJOLI, Luigi. Derecho y razón. Trad. Perfecto A. Ibañez et allii. Título original: Diritto e ragione. Madrid: Trotta, 1995. 991p.

IPPOLITO, Dario. O garantismo de Luigi Ferrajoli. Tradução Hermes Zaneti Júnior. Revista de Estudos Constitucionais, Hermenêutica e Teoria do Direito - RECHTD, Unisinos, jan./jun. 2011. Disponível em: http://revistas.unisinos.br/index.php/RECHTD/article/view/733. Acesso em: 25 maio 2016.

JULIOS-CAMPUZANO, Afonso de. Constitucionalismo em tempo de globalização. Tradução José Luis Bolzan de Morais e Valéria Ribas do Nascimento. Porto Alegre: Livraria do Advogado, 2009.

MASTRANGELO, Cláudio. Agências reguladoras e participação popular. Porto Alegre: Livraria do Advogado, 2005. 


\section{Democracia}

MOREIRA NETO, Diogo de Figueiredo. Mutações do direito administrativo. 13. ed. Rio de Janeiro: Renovar, 2007. MOREIRA NETO, Diogo de Figueiredo. Relações entre Poderes e Democracia: crise e superação. Belo Horizonte: Fórum, 2014.

OLIVEIRA NETO, Francisco José Rodrigues de. A consolidação do estado constitucional de direito no Brasil. Revista Eletrônica Direito e Política, Programa de Pós-Graduação Stricto Sensu em Ciência Jurídica da Univali, Itajaí, v. 7, n. 3, 3o quadrimestre de 2012. Disponível em: www.univali.br/direitoepolitica. ISSN 1980-7791. Acesso em: 15 maio 2016.

PAZZOLO, Susana. Un constitucionalismo ambiguo. In: CARBONAL, Miguel (org.). Neoconstitucionalismo(s). Madrid: Editorial Trotta, 2009.

VALDÉS, Ernesto Garzón. Algo más acerca del "coto vedado". Doxa, Cuadernos de Filosofía del Derecho, n. 6, p. 209 213, 1989. Disponível em: http://www.cervantesvirtual.com/servlet/SirveObras/01361620813462839088024/ cuaderno6/Doxa6_12.pdf. Acesso em: 16 nov. 2015. 